\title{
Gitelman Syndrome Diagnosed in a Woman in the Second Trimester of Pregnancy
}

\author{
$\underline{\text { Sıla Cetik }}^{1}$, Nursel Calik Basaran ${ }^{1}$, Lale Ozisik ${ }^{1}$, Serife Gul Oz ${ }^{1}$, Mustafa Arici ${ }^{2}$ \\ ${ }^{1}$ Department of Internal Medicine, Faculty of Medicine, Hacettepe University, Sihhiye, Ankara, Turkey \\ ${ }^{2}$ Department of Nephrology, Faculty of Medicine, Hacettepe University, Sihhiye, Ankara, Turkey
}

Received: 24/03/2019

Accepted: 27/03/2019

Published: $24 / 04 / 2019$

\begin{abstract}
How to cite this article: Çetik S, Calik NC, Ozisik L, Gul Oz S, Arici M. Gitelman syndrome diagnosed in a woman in the second trimester of pregnancy. EJCRIM 2019;6: doi:10.12890/2019_001100.
\end{abstract}

Conflicts of Interests: The Authors declare that there are no competing interests.

This article is licensed under a Commons Attribution Non-Commercial 4.0 License

\section{ABSTRACT}

Gitelman syndrome is a rare renal tubule disease characterized by hypokalaemia, metabolic alkalosis, hypomagnesaemia, hypocalciuria and normal blood pressure. It shows autosomal recessive inheritance and is usually not diagnosed until late childhood or adulthood. We report the case of 34-year-old woman who at 21 weeks of pregnancy was admitted to the gynaecology department for abdominal pain, muscle cramps and weakness. Routine blood tests showed hypokalaemia ( $2.32 \mathrm{mEq} / \mathrm{l})$, hypomagnesaemia (1.18 mEq/l), compensated metabolic alkalosis ( $\mathrm{pH} 7.439$, bicarbonate $26.1 \mathrm{mmol} / \mathrm{l})$, increased urinary magnesium excretion (140.25 mg/day, normal range 73-122 mg/day) and reduced urinary calcium excretion ( $49.25 \mathrm{mg} /$ day, normal range $100-250 \mathrm{mg} /$ day). In light of these findings, the patient was diagnosed with Gitelman syndrome and optimum potassium and magnesium levels were maintained with oral supplements.

\section{LEARNING POINTS}

- Gitelman syndrome is a rare genetic disease which can affect women of childbearing age.

- There is no evidence-based treatment algorithm for treating pregnant patients with Gitelman syndrome.

- Electrolyte disturbances and their treatment in pregnant patients can be challenging since many drugs have limited safety data.

\section{KEYWORDS}

Gitelman syndrome, pregnancy, hypokalemia, hypocalciuria

\section{CASE DESCRIPTION}

We report the case of 34-year-old woman who at 21 weeks of pregnancy was admitted to the gynaecology department with abdominal pain, muscle cramps and weakness. Her history was unremarkable except for hypothyroidism. Her vital signs and physical examination were normal, but routine blood tests revealed electrolyte disturbances: her serum potassium level was $2.32 \mathrm{mEq} / \mathrm{l}$ (normal range 3.5-5.1 mEq/l) and her magnesium level was $1.18 \mathrm{mEq} / \mathrm{l}(1.8-2.6 \mathrm{mEq} / \mathrm{l})$. As the patient was symptomatic, $80 \mathrm{mEq}$ potassium chloride was administered intravenously and her symptoms gradually improved.

The patient was referred to the internal medicine department for investigation of the hypokalaemia. She had no history of drug use other than iodine, folic acid, iron and levothyroxine sodium replacement. There was no family history of renal disease, and renal ultrasound and function tests were in the normal range. The results of a 24-hour urine test revealed calcium excretion $49.25 \mathrm{mg} / \mathrm{day}$ (normal range $100-250$ $\mathrm{mg} /$ day), magnesium excretion $140.25 \mathrm{mg} /$ day (73-122 mg/day), potassium excretion $82.5 \mathrm{mEq} /$ day (25-125 mEq/day), sodium excretion $260 \mathrm{mEq} /$ day and chloride excretion $257.5 \mathrm{mEq} /$ day. Blood gas analysis showed compensated metabolic alkalosis $\left(\mathrm{pH} 7.439, \mathrm{HCO}{ }_{3} 26 \mathrm{~mol} / \mathrm{l}\right.$, $\mathrm{pCO}_{2} 45 \mathrm{mmHg}$ ). The serum renin level was $30.25 \mathrm{pg} / \mathrm{ml}$ and the aldosterone level was $130 \mathrm{pg} / \mathrm{ml}$, which were both within the normal range. 
In light of the above results, the patient was diagnosed with Gitelman syndrome (GS). During hospitalization, she was treated with daily intravenous potassium chloride (120 mEq/day) and magnesium sulfate ( $3 \mathrm{~g} /$ day). At follow-up, her potassium level ranged between 2.5 and $3.7 \mathrm{mEq} / \mathrm{l}$ and her magnesium level between 1.18 and $1.86 \mathrm{mg} / \mathrm{dl}$. She remained asymptomatic. Intravenous treatment was then changed to oral supplementation, which maintained optimal electrolyte levels. The patient was discharged on $80 \mathrm{mEq} / \mathrm{day}$ oral potassium citrate and $365 \mathrm{mg} /$ day oral magnesium sulfate and advised to consume a potassium-rich diet.

\section{DISCUSSION}

GS is an autosomal-recessive disorder which affects the $\mathrm{NaCl}$ cotransporter located at the distal renal tubules and was first described in 1966 by Gitelman et al. ${ }^{[1]}$. It is characterized by hypokalaemia, hypomagnesaemia, metabolic alkalosis and low urinary calcium excretion. In most cases high blood pressure is not present but there are disturbances in the renin-angiotensin-aldosterone axis. The condition is caused by a mutation in the SLC12A3 gene on chromosome 16 which results in a loss of function in the sodium-chloride cotransporter in the distal tubules $^{[2,3]}$. This loss of function induces potassium and magnesium wasting and eventually results in hypokalaemia and hypomagnesaemia. Since the renin-angiotensin-aldosterone axis is hyperactive in GS, we expected a high renin concentration in our patient, but levels were in the normal range.

GS can affect women of childbearing age, but there is little information in the literature on the management of pregnant patients with this syndrome. Normalization of electrolytes can be a challenge in normal patients with GS, and even more so in pregnant patients with GS as their renal function undergoes significant changes ${ }^{[4]}$. Nevertheless, most patients have healthy pregnancies and favourable outcomes, although a few adverse fetal outcomes have been reported in the literature ${ }^{[5-7]}$. Pregnancy itself increases the potassium and magnesium needs of the body as documented by many researchers including Talaulikar et al. in 2005, who reported a sixfold increase in the potassium and magnesium demands of their patient ${ }^{[8]}$. Since hyperemesis gravidarum can increase hyperkalaemia, pregnant patients with GS should be carefully monitored. However, Basu et al. suggested that normalization of potassium and magnesium levels is not essential for a good obstetric and fetal outcome ${ }^{[9]}$. Consequently, asymptomatic patients can be merely observed without therapy, but symptomatic patients exhibiting fatigue, cramps and tetany should be treated immediately. Oral potassium and magnesium supplements are still the cornerstones of therapy ${ }^{[8]}$. When these supplements are insufficient, potassium-sparing diuretics can be an option. Spironolactone is a category $\mathrm{C}$ drug in pregnancy, but there are case reports of its use without apparent complications in pregnant GS patients ${ }^{[10,11]}$. Other potassium-sparing drugs such as amiloride and eplerenone, both class B drugs in pregnancy, could be a better alternative to spironolactone in resistant GS ${ }^{[12,13]}$. Our patient's electrolytes stabilized with oral supplements and there was no need for potassium-sparing diuretics.

It is essential to identify the gene mutation in order to distinguish GS from pseudo-GS in pregnant women ${ }^{[14]}$. However, in developing countries, genetic testing is expensive and not always possible. Also, since the clinical approach is the same for both conditions, it is not cost effective to genetically test every patient with GS. In our case, the patient did not accept genetic testing so we were unable to identify whether or not she had a mutation: our successful treatment plan was based on the diagnosis of GS without confirmation of an SLC12A3 mutation.

In conclusion, pregnant women with GS should be carefully managed. Evidence-based treatment guidelines are lacking and so treatment should be personalized. The main aim is to ensure an asymptomatic, uncomplicated pregnancy and the best fetal outcome using minimal drug therapy. Patients should be monitored carefully for pregnancy complications, electrolyte imbalances and drug side-effects.

\section{REFERENCES}

1. Gitelman HJ, Graham JB, Welt LG. A new familial disorder characterized by hypokalemia and hypomagnesemia. Trans Assoc Am Phys 1966;79:221-235.

2. Simon DB, Nelson-Williams C, Bia MJ, et al. Gitelman's variant of Bartter's syndrome, inherited hypokalaemic alkalosis, is caused by mutations in the thiazide-sensitive Na-Cl cotransporter. Nat Genet 1996;12:24.

3. Peters M, Jeck N, Reinalter S, et al. Clinical presentation of genetically defined patients with hypokalemic salt-losing tubulopathies. Am J Med 2002;112:183-190.

4. Cheung KL, Lafayette RA. Renal physiology of pregnancy. Adv Chronic Kidney Dis 2013;20:209-214.

5. Nand N, Deshmukh AR, Mathur R, Chauhan V, Brijlal. Gitelman syndrome: presenting during pregnancy with adverse foetal outcome. J Assoc Physicians India 2016;64:104-105.

6. de Haan J, Geers T, Berghout A. Gitelman syndrome in pregnancy. Int J Gynaecol Obstet 2008;103:69-71.

7. McCarthy FP, Magee CN, Plant WD, Kenny LC. Gitelman's syndrome in pregnancy: case report and review of the literature. Nephrol Dial Transplant 2010;25:1338-1340.

8. Talaulikar GS, Falk MC. Outcome of pregnancy in a patient with Gitelman syndrome: a case report. Nephron Physiol 2005;101:35-38.

9. Basu A, Dillon RD, Taylor R et al. Is normalisation of serum potassium and magnesium always necessary in Gitelman syndrome for a successful obstetric outcome? BJOG 2004;111:630-634.

10. Croves TD, Corenblum B. Spironolactone therapy during human pregnancy. Am J Obstet Gynecol 1995;172:1655-1656.

11. de Arriba G, Sánchez-Heras M, Basterrechea MA. Gitelman syndrome during pregnancy: a therapeutic challenge. Arch Gynecol Obstet 2009;280:807-809.

12. Morton A, Panitz B, Bush A. Eplerenone for Gitelman syndrome in pregnancy. Nephrology (Carlton) 2011;16:349.

13. Mascetti L, Bettinelli A, Simonetti GD, et al. Pregnancy in inherited hypokalemic salt-losing renal tubular disorder. Obstet Gynecol 2011;117(2 Pt 2):512-516.

14. Yoshihara M, Sayo A, Mayama M, Oguchi H. Pseudo Gitelman syndrome associated with pregnancy. Obstet Gynecol 2015;126:877-880. 